\title{
DESIGN OF THIN WALL STRUCTURES FOR ENERGY ABSORPTION APPLICATIONS: DESIGN FOR CRASH INJURIES MITIGATION USING MAGNESIUM ALLOY
}

\author{
F. Tarlochan ${ }^{1}$, Samer. $F^{2}$ \\ Center for Design and Innovation, College of Engineering, Universiti Tenaga Nasional, Malaysia
}

\begin{abstract}
This paper describes a computational investigation on the response of thin wall structures due to dynamic compression loading. In this paper, the tubes subjected for both direct and oblique loading. Several different cross-sectional structures have been studied to specify the best one. Initially the tubes were subjected to direct loading, and then the tubes were subjected to oblique loading. After that, the tubes were compared to obtain the cross section which fulfills the performance criteria. The selection was based on multi criteria decision making (MCDM) process. The performance parameters taken in this study are the specific energy absorbed by the tube for both direct and oblique, crush force efficiency and the ratio between the energy absorbed by direct and oblique loading. Trigger and foam filled are implemented to study their effects on the parameters used. The study used the magnesium alloy as a material to study potentially the possibility and ability of using the magnesium alloy in the energy absorber parts since the magnesium has lighter weight.
\end{abstract}

Index Terms: dynamic compression, thin wall, energy absorption, direct oblique loading

\section{INTRODUCTION}

It is known that thousands of people throughout the world are killed or seriously injured due to collisions every year.[1] showed the problem of causalities as a result of road accidents is acknowledged to be a global phenomenon in all countries around the world because of the growth in number of people. The dangerous comes from the impact energy that transmit to the car occupant and hence to the passengers. To keep passengers safe the impact energy transmitted to the passengers should be as low as possible. To minimize the impact energy it is necessary to dissipate the energy comes from collision by absorbing the energy through deformation of car structure; this will reduce the risk and hence will keep the passengers more safe. It is necessary to find out a method to increase the car structure members' ability to absorb impact energy as much as possible and allow an acceptable energy passes to the passengers. The structures are called frontal longitudinal as shown in Figure 1.

Many researchers have done to improve the energy absorption of these structures due to axial impact [2]. However in the context of a vehicle collision, the vehicles energy absorbers are commonly subjected to both axial and oblique (off-axis) loads. If compared with axial loading conditions, relatively few studies have been conducted on the energy absorption response of thin walled tubes under oblique loads [4]. Some of the well cited works in this oblique impact are works of Borvik et al. [5],
Reyes et al. [6-8] and Reid et al. [9]. When the vehicle is subjected to an oblique loading, the frontal longitudinal collapses in a bending mode rather than axial crush [10], this causes to lower energy absorption capability of the frontal longitudinal.

Some researchers have considered foams for energy absorption. Foam used as a filler which might be metallic or polymeric [1117]. It was concluded that using of foam leads to increase the energy absorption capability for tubular structures and decreases the energy absorption stroke (crush length of tube). And this is useful especially when designing compact cars.

Recently, the researchers trend to the computer simulation (finite element analysis-FEA) instead of experimental work. FEA widely used for analysis and optimization. In impact studies, FEA has shown to be able and useful tools to understand the deformation and responses of the energy absorber tubes under impact loading [18, 19]. Using FEA reduces time and cost which may uses in the experimental work. The objective of this study is to design an efficient thin wall tube as an energy absorber by using finite element analysis

\section{DESIGN METHODOLOGY}

Six different walled tubular cross sectional profiles were designed. The profiles are circular, square, rectangular, hexagonal, octagonal and ellipse. The tubular structures 
material was modeled as magnesium alloy (AZ31). The perimeter of the six profiles, the length and the thickness were kept constant. This was carried out just to investigate the various cross sectional profile crash performance. The length and the thickness were chosen to be $350 \mathrm{~mm}$ and $2 \mathrm{~mm}$ respectively. Two different perimeter lengths were chosen $300 \mathrm{~mm}$ and $372 \mathrm{~mm}$ respectively. From these six profiles, one of them will be chosen by Multi Criteria Decision Making (MCDM) process. After that the study enhances the crash performance of the chosen profile. The foam filler material includes to that profile namely aluminium foam with density of $534 \mathrm{~kg} / \mathrm{m} 3$. The dynamic simulations for tube and foam filled tube include direct and oblique loading (30 degrees off the tubular longitudinal axis). The initial velocity used in the simulations was $15 \mathrm{~m} / \mathrm{s}$ with an impact mass of $275 \mathrm{~kg}$. The values of the velocity and mass are discussed in the next section. The values are given in Table 1 .

Table 1: Geometry and dimensions of tubes used for study

\begin{tabular}{|c|c|c|c|c|c|c|c|}
\hline Profile & $\begin{array}{c}\text { Specimen } \\
\text { ID }\end{array}$ & $\begin{array}{c}\text { Perimeter } \\
(\mathrm{mm})\end{array}$ & $\begin{array}{l}\text { Length } \\
(\mathrm{mm})\end{array}$ & $\begin{array}{c}\text { Mass } \\
(\mathrm{kg})\end{array}$ & $\begin{array}{c}\text { Major } \\
\text { Dimension } \\
(\mathrm{mm})\end{array}$ & $\begin{array}{l}\text { Thickness } \\
\text { (mm) }\end{array}$ & $\begin{array}{l}\text { Profile } \\
\end{array}$ \\
\hline Circular & $\begin{array}{l}\text { C_300 } \\
\text { C_372 }\end{array}$ & $\begin{array}{l}300 \\
372\end{array}$ & 350 & $\begin{array}{l}1.7 \\
2.0\end{array}$ & $\begin{array}{l}\text { Diam. }=95.5 \\
\text { Diam. }=118.1\end{array}$ & 2 & \\
\hline Rectangle & $\begin{array}{l}\text { R_300 } \\
\text { R_372 }\end{array}$ & $\begin{array}{l}300 \\
372\end{array}$ & 350 & $\begin{array}{l}1.7 \\
2.0\end{array}$ & $\begin{array}{l}90 \times 60 \\
112 \times 74\end{array}$ & 2 & \\
\hline Square & $\begin{array}{l}\text { S_300 } \\
\text { S_372 }\end{array}$ & $\begin{array}{l}300 \\
372\end{array}$ & 350 & $\begin{array}{l}1.7 \\
2.0\end{array}$ & $\begin{array}{l}75 \times 75 \\
93 \times 93\end{array}$ & 2 & \\
\hline Hexagonal & $\begin{array}{l}\text { H_300 } \\
\text { H_372 }\end{array}$ & $\begin{array}{l}300 \\
372\end{array}$ & 350 & $\begin{array}{l}1.7 \\
2.0\end{array}$ & $\begin{array}{l}50 \text { each side } \\
62\end{array}$ & 2 & \\
\hline Octagonal & $\begin{array}{l}\text { O_300 } \\
\text { O_372 }\end{array}$ & $\begin{array}{l}300 \\
372\end{array}$ & 350 & $\begin{array}{l}1.7 \\
2.0\end{array}$ & $\begin{array}{l}37.5 \text { each } \\
\text { side } \\
46.5\end{array}$ & 2 & \\
\hline Ellipse & $\begin{array}{l}\text { E_300 } \\
E_{-} 372\end{array}$ & $\begin{array}{l}300 \\
372\end{array}$ & 350 & $\begin{array}{l}1.7 \\
2.0\end{array}$ & $\begin{array}{l}62,31 \\
74,37\end{array}$ & 2 & \\
\hline
\end{tabular}

\section{Peak Force, FMAX}

The peak force of a component is the highest load required to cause significant permanent deformation or distortion. The peak load is of concern for two reasons. The first is that at low-speed and low-energy impacts, it is desirable that no permanent deformation takes place, as this would be considered damage to the structure. Secondly the peak load is often the maximum load observed in the useful stroke of the energy absorbing device and as such has a direct importance on the loading of the vehicle occupant.

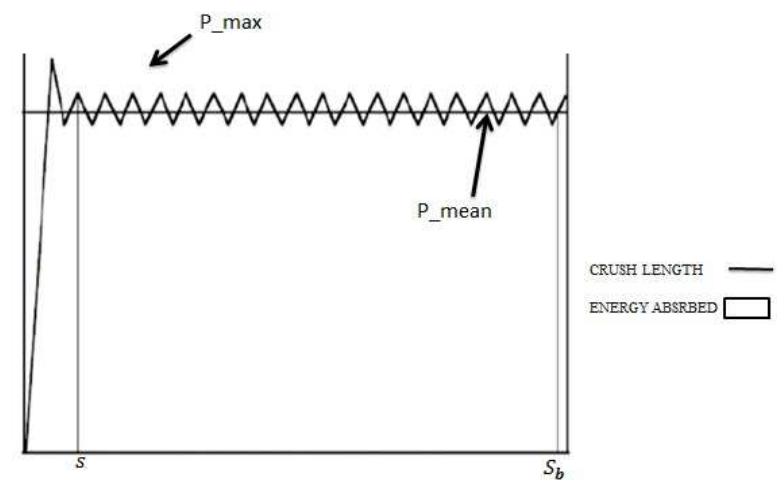

Figure 2: Force displacement characteristics [20]

\section{Energy Absorption, Es}

The energy absorption performance can be calculated from the load-displacement curve. Energy absorption EA is denoted as an integration of a load-displacement curve as shown in Figure 2

$\mathrm{EA}=\int_{0}^{B \mathrm{~b}} \mathrm{p} \cdot \mathrm{d} \delta$

When $\mathrm{p}$ is an instantaneous crushing load, $\delta \mathrm{b}$ is the length of crushing specimen. From the equation (1).

$\mathrm{EA}=\int_{0}^{\delta \mathrm{b}} \mathrm{p} \cdot \mathrm{d} \delta=\mathrm{P}_{\mathrm{m}}(\delta \mathrm{b}-\delta \mathrm{i})$

Where $\mathrm{P}_{\mathrm{m}}$ is the mean crushing load, 81 is the initial length of the crushing specimen. An ideal energy absorption could achieve a maximum force and keep it constant during the entire deformation length.

\section{Crush Force Efficiency, CFE}

The crush force efficiency (CFE) can be defined as a mean crushing force $\left(\mathrm{P}_{\text {mean }}\right)$ divided by peak crushing load $\left(\mathrm{P}_{\text {peak }}\right)$ as follows.

$\mathrm{CFE}=\frac{\mathbf{p}_{\text {manan }}}{\mathbf{P}_{\text {paik }}}$

The crush force efficiency is very important parameter used to evaluate the performance of energy absorbing structures [21]. A value of unity of the energy absorber member represents an ideal energy absorber which represents a value of the crush force efficiency corresponding to the constant loaddisplacement curve [22], while the low values indicate happening of greater peaks of force during crushing [23]. Low values of crush force efficiency means high peaks force which 
leads to increasing in acceleration and potential damage to the passengers during frontal impact which must be avoided. CFE is related to the structural effectiveness and it is an important measure for car structure to know how efficient it is [24]. High values of $\mathrm{CFE}$ are desirable and must be maximized and this can be obtained by decreasing the peak load. Introducing trigger mechanism is usually used to decrease the peak load and thus increases the CFE value. [25] Showed that the crush force efficiency can be increased by increasing the wall thickness of the tube.

\section{Specific energy absorption (S.E.A)}

The most significant features of the longitudinal members are the Specific energy absorption (SEA). Which is define as the energy absorbed (EA) per unit mass and can be denoted as follows.

$$
\mathrm{SEA}=\frac{E A}{m}
$$

Where $(m)$ is the original undeformed mass (before impact). The specific energy absorption is a measure of energy absorption capability of a structural component. The higher values of (SEA) are an indicator of the light weight crush members [26]. The specific energy absorption is an indicator of how efficient the absorber is. So the term is used to compare the ability among absorbers. High value of specific energy absorption can be gotten by decreasing the absorber mass, since the specific energy absorption depends on the density of the absorber material. Researches done on the energy absorption behavior stated that the using of tubular concept is most efficient energy absorption concepts evaluated [27]. It was found that the use of foam-filled tubes will increase the unreformed tube mass. By using foam-filled specific energy absorption will increase and it also increase by increasing the foam density [28].

\section{Stroke efficiency}

The stroke efficiency of structure $S_{E}$ is the ratio between the maximum energy absorber crush lengths to the original absorber length which can be expressed as follow.

$$
S_{E}=\frac{d_{\max }}{l}
$$

Where $d_{\max }$ is the maximum crush length of the energy absorber at when the compaction occurs and the energy absorption is at in maximum level, and ${ }^{l}$ is the original length of the absorber. Also it is a measure of how the performance of a structure reaches to the best possible performance [29]. A unity value of stroke efficiency represents the ideal case of the energy absorber, but in reality the value is always less than unity. They also concluded that the stroke efficiency decreased rapidly when the wall thickness increased and it increased when the length increased.

For the multi criteria decision making (MCDM) process, the complex proportional assessment method (COPRAS) was chosen $[30,31]$. This method was chosen for its simplicity in usage. The method assumes direct and proportional dependences of the significance and utility degree of the available alternatives under the presence of mutually conflicting criteria. It takes into account the performance of the alternatives with respect to different criteria and the corresponding criteria weights [30]. This method selects the best decision considering both the ideal and the ideal-worst solutions. The COPRAS method is a successful method to solve problems of design selection in many fields like construction, project management, and economy. This method consists of many steps, and they are explained as follows:

\section{Step 1: Developing the Initial Matrix (X) and Find the Relative Coefficient (R)}

This first step involves the generation of a simple matrix which maps the alternatives (design concepts) to the selection criteria. This matrix is labeled as $\mathrm{X}$ as given in equation3.

$$
X=\left[x_{i j}\right]_{m X n}=\left[\begin{array}{cccc}
x_{11} & x_{12} & \ldots & x_{1 n} \\
x_{21} & x_{22} & \ldots & x_{2 n} \\
\vdots & \vdots & \vdots & \vdots \\
x_{m 1} & x_{m 2} & \ldots & x_{m n}
\end{array}\right]
$$

$(i=1,2 \cdots m),(j=1,2 \cdots n)$

Where $x i j$ is the performance value of ith alternative on jth criterion, $\mathrm{m}$ is the number of alternatives (design concepts) compared and $\mathrm{n}$ is the number of criteria. The problem in design selection is that most design criteria are not in the same dimensions or units. This makes selection a little harder. One way to overcome this is to convert the entire matrix $\mathrm{X}$ to a nondimensionalized matrix R. This way, it is easier to compare between selection criteria. The entry xij represents the positive (absolute) value for each criteria and $\sum x i j$ is the summation for a number of positives decisions. The importance of the relative coefficient is to reduce the values of the criteria to make it easy for comparing. The symbol of the relative coefficient is $\mathrm{R}$ and it is formulated as

$$
R=\left[r_{i j}\right]_{m X n}=\frac{x_{i j}}{\sum_{i=1}^{m} x_{i j}}
$$




\section{Step 2: Determining the Weighted Normalized Decision Matrix D.}

The sum of dimensionless weighted normalized values of each criterion is always equal to the weight for that criterion.

$D=\left\lfloor y_{i j}\right\rfloor=r_{i j} \quad x \quad w_{j}$

Where rij is the normalized performance value of ith alternative on jth criterion and wj is the weight of jth criterion. as given in equation 6.

$\sum_{i=1}^{m} y_{i j}=w_{j}$

To determine or compute the individual weightage for each criteria wj, the following method can be used:

Compare two criteria at a time. Total comparison sets $(\mathrm{N})$ is equal to $N=\frac{n(n-1)}{2}$ where $\mathrm{n}$ is the number of selection criteria.

Amongst the two criteria being selected, the criterion which is more important is given a score of 3 whereas the criterion which is least important is given a score of 1 . If both criteria are of equal importance, a score of 2 is given. Repeat this for all other criteria.

The total score obtain for each criteria is computed as

$\sum_{i=1}^{m} N_{i j}=W_{j}$

A relative emphasis weighting factor, wj, for each selection criteria is obtained by dividing the total score for each selection criteria $(\mathrm{Wj})$ by the global total score $\sum_{j=1}^{m} W_{j}=G$. (Refer Table 2 for example)

\section{Step 3: Summing of Beneficial and non-Beneficial}

\section{Attributes}

The beneficial and non-beneficial attributes are in the decision matrix. The greater beneficial attribute is better selection also the low value of non-beneficial attribute is better selection too. After specify these attributes, the next step is to separate these values by their sums. The sums of the attributes can be formulated as in equations below:

\begin{tabular}{|c|c|c|c|c|c|c|c|c|c|c|c|c|}
\hline \multirow{2}{*}{$\begin{array}{l}\text { Selection } \\
\text { Criteria }\end{array}$} & \multicolumn{10}{|c|}{ Number of Comporison Sets, $N=5(5-1) / 2=10$} & \multirow{2}{*}{ W } & \multirow{2}{*}{ W } \\
\hline & 1 & 2 & 3 & 4 & 5 & 6 & 7 & 8 & 9 & 10 & & \\
\hline A & 3 & 3 & 2 & 2 & & & & & & & 10 & $\begin{array}{l}10 / 40 \\
=0.25\end{array}$ \\
\hline B & 1 & & & & 2 & 1 & 2 & & & & 6 & $\begin{array}{l}6 / 40 \\
=0.15\end{array}$ \\
\hline C & & 1 & & & 2 & & & 2 & 1 & & 6 & $\begin{array}{l}6 / 40 \\
=0.15\end{array}$ \\
\hline 0 & & & 2 & & & 3 & & 2 & & 2 & 9 & $\begin{array}{l}9 / 40 \\
=0.225\end{array}$ \\
\hline E & & & & 2 & & & 2 & & 3 & 2 & 9 & $\begin{array}{l}9 / 40 \\
=0.225 \\
\end{array}$ \\
\hline & & & & & & & & & & $\Sigma$ & $G=40$ & 1 \\
\hline
\end{tabular}

$S_{+1}=\sum_{j=1}^{n} y_{+i j}$

$S_{-1}=\sum_{j=1}^{n} y_{-i j}$

Where $y+i j$ and $y-i j$ are the weighted normalized values of both the beneficial and non-beneficial attributes respectively. The high value of $\mathrm{S}+\mathrm{i}$, the better is the design concept, and the lower the value of $\mathrm{S}-\mathrm{i}$, the better is the design concept. Just to note $\sum_{\text {that }} \sum_{\text {i }}$ and $\sum$ S-i of the design concepts are always respectively equal to the sums of weights for the beneficial and non-beneficial attributes as expressed by the following equation

$$
\begin{gathered}
\text { Sum }_{\text {positive }}=\sum_{i=1}^{m} S_{+i}=\sum_{i=1}^{m} \sum_{j=1}^{n} y_{+i j} \\
S_{\text {uegative }}=\sum_{i=1}^{m} S_{-i}=\sum_{i=1}^{m} \sum_{j=1}^{n} y_{-i j}
\end{gathered}
$$

The summation equation 9 and 10 is always equals to one.

\section{Step 4: Relative Significance or Priority (Q)}

The higher value of the relative significance is the best choice. The relative significance can be denoted in the formula as below:

$$
Q_{i}=S_{+i}+\frac{S_{-\min } \sum_{i=1}^{m} S_{-i}}{S_{-i} \sum_{i=1}^{m}\left(S_{-\min } / S_{-i}\right)}
$$

Where $\mathrm{S}-\mathrm{min}$ is the minimum value of $\mathrm{S}-\mathrm{i}$

\section{Step 5: Determining the Quantitative Utility $(U i)$}

Table 2: Example of weight age setting 
Calculation of qualitative utility (Ui) which directly related to the $(\mathbf{Q} \mathbf{l})$ value as mentioned in equation. From the equation it can be observed that the quantitative utility is directly proportionate to the relative significance. The maximum relative significance value is denoted as Qmax.

$$
\mathrm{U}_{\mathrm{i}}=\frac{\mathrm{Q}_{\mathrm{i}}}{\mathrm{Q}_{\max }}
$$

\section{DYNAMIC ANALYSIS}

Finite element codes ABAQUS/Explicit version 6.10 has been used in this study to model the response of energy absorbers and hence the frontal car subjected to dynamic impact loading under full overlap, offset overlap and oblique loading. ABAQUS is capable to simulate problems in various ranges as structural field, thermal electrical analysis, heat transfer, soil mechanics acoustics and piezoelectric. In implicit, the simulations take several orders of magnitude fewer increments than an explicit simulation in spite of the cost per increment is much greater. Explicit methods require a small time increment. ABAQUS/Explicit that operates explicit dynamic is suitable to model high speed dynamic and this is costly to analyses by using implicit methods. ABAQUS/Explicit is suitable to analyze the transient dynamic of the structures which subjected to impact loading [4]. It is possible to solve complicated, very general, three-dimensional contact problems with deformable bodies in ABAQUS/Explicit. Problems involving stress wave propagation can be far more efficient computationally in ABAQUS/Explicit. Energy absorbers deform to absorb energy under quasi-static or dynamic loading. So ABAQUS/Explicit is used in this study to model nonlinear loading of the energy absorbers.

\subsection{Finite Element Modeling}

In this study, finite element (FE) models of both empty and foam filled tubes were developed using the non-linear FE code ABAQUS-Explicit. The code was used to predict the response of the thin wall tubes subjected to a free falling impinging mass. The whole model comprises principally of the thin wall structure under study, the falling mass (striker), and the base. The thin wall structure was modeled by using 4 node shell continuum (S4R) elements with 5 integration points along the thickness direction of the element. The foam was modeled using 8-noded continuum elements with the reduced integration techniques in combination with hourglass control. Stiffnessbased hourglass control was used to avoid artificial zero energy deformation modes and reduced integration was used to avoid volumetric locking. Elements size of $5 \mathrm{~mm}$ were chosen for the shells and foam elements, respectively, based on a mesh convergence study. A mesh convergence is important to ensure a sufficient mesh density to accurately capture the deformation process. The contact algorithm used to simulate contact interaction between all components was the "general contact algorithm". This is important to avoid interpenetration of tube wall. This algorithm is less intense in terms of computational time. Contact between the tube walls and tube walls with the foam were modeled as finite sliding penalty based contact algorithm with contact pairs and hard contact. The value of the Coulomb friction coefficient for all contact surfaces was set at $0.2[25,26]$.

The striker was modeled as a rigid body with only one allowable translational displacement while all other translational and rotations degree of freedom were fixed. The impact velocity of the striker on the tubes was modeled to be 15 $\mathrm{m} / \mathrm{s}(54 \mathrm{~km} / \mathrm{h})$ with a lumped mass of $275 \mathrm{~kg}$. (The impact speed value was taken based from the New Car Assessment Program (NCAP) by the National Highway Traffic Safety Administration (NHTSA). The mass was assumed to be $25 \%$ of a compact car $(1100 \mathrm{~kg})$. It is assumed that each tubular energy absorbing structure is capable of absorbing an equivalent kinetic of $275 \mathrm{~kg}$ mass since in reality the maximum energy that can be absorbed by two tubes in service is much less than $50 \%$ [33].

The wide range of elements is available in ABAQUS which are used to create the models. However, the extensive element library provides a powerful set of tools for solving many different problems, the figure (3) shows the type of element.

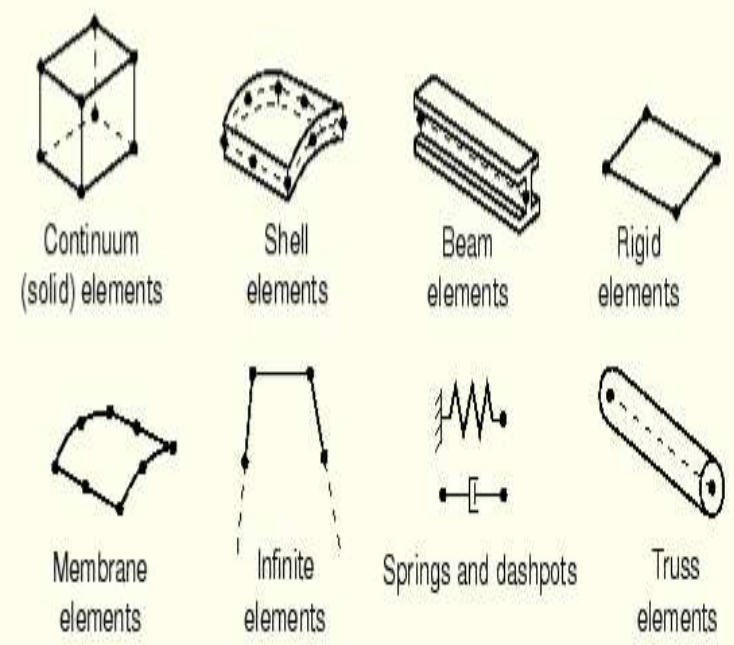

Figure 3: Commonly used element families in ABAQUS/Explicit

(ABAQUS Version 6.6 documentation)

Shell element has been used to model thin-walled tube since shell element is suitable when the thickness of the tube is less than $1 / 10$ of the height. All the absorbers have been modeled used in this finite element simulation were generated by using the element S4R. This element is a three-dimensional doubly 
curved four node shell element. Each node has threedisplacement and three-rotation degrees of freedom. While the two rigid plates modeled by using three-dimensional four-node rigid element R3D4. One of the two plates was fixed in all degree of freedom except in the direction of the applied load, while the other plate was fixed by constraining the whole degrees of freedom.

\subsection{Loading, Interaction and Boundary Conditions}

The tube was completely fixed to a rigid body (plate) from one end using tied constraint. This constraint makes the motion along with all displacement in linear and rotation degrees of freedom of all the nodes on the tube base edge the same of the rigid body. The plate was modeled as a rigid surface. Rigid surfaces are efficient analytical for contact simulations they are not element and don't need to specify masses, suctions, and stress-strain. The other ends of the tube will constraint in all degree of freedom except in the direction of the moving impactor which will move axially towards the fixed plate. Two reference points will be defined, on the rigid plates, one on the fixed one which the reactions can be calculated and the second one will be defined on the moving plate (impactor) which at this point the masses and velocity can be defined.

Dynamic loading is simulated at the second reference point which mass and velocity have been defined. Step time can be defined in ABAQUS/Explicit by creating step and then by choosing dynamic, explicit and then specify the time period, long time period needs a long time to visualized the result and need high CPU capability. Period time depends on the nature of structure and also the mesh size.

Interaction has been done on all the parts of the structures. Interaction is available in ABAQUS/Explicit. For the tube walls and for the aluminium foam, self-contact between the

walls must be defined while surface to surface contact should be defined between each rigid plate and the tube, between each part of telescope and another also between the tube and each part of telescope. Interaction option will be done after defining the contact surface and specify the friction coefficient "penalty". The surface-to-surface contact based on master-slave type. Constraints were done between the fixed rigid plate and the end of tube and between the fixed rigid and the end of the last part of telescope. That's mean contact can be done between deformable surfaces or between deformable surfaces and rigid surfaces. Mesh then defined by specify the mesh size $5 \mathrm{~mm}$ size was used in this study according to [31], [32].

\section{RESULTS AND DISCUSSION}

Summary of the results obtain in this study is presented in Tables $5-6$ for convenience. Detail discussions and explanations will be given in the accompanying sub sections.
Table 5: Summary of crashworthiness parameters for all tube profiles for two different parameters (direct loading)

\begin{tabular}{|c|c|c|c|c|c|c|c|c|c|c|c|c|}
\hline \multirow[b]{2}{*}{$\begin{array}{l}\text { Indica } \\
\text { tors }\end{array}$} & \multicolumn{2}{|c|}{ Circular } & \multicolumn{2}{|c|}{ Rectangle } & \multicolumn{2}{|c|}{ Square } & \multicolumn{2}{|c|}{ Hexagonal } & \multicolumn{2}{|c|}{ Octagonal } & \multicolumn{2}{|c|}{ Ellipse } \\
\hline & $\begin{array}{c}6 \\
\text { Direct } \\
300\end{array}$ & $\begin{array}{c}6 \\
\text { Direct } \\
372\end{array}$ & $\begin{array}{c}\text { R. } \\
\text { Direct } \\
300\end{array}$ & \begin{tabular}{|c|}
$R \cdot$ \\
Direct \\
372
\end{tabular} & $\begin{array}{l}\text { S. } \\
\text { Direct } \\
300\end{array}$ & \begin{tabular}{|c} 
S. \\
Direct \\
372
\end{tabular} & $\begin{array}{c}H . \\
\text { Direct } \\
300\end{array}$ & $\begin{array}{c}H \cdot \\
\text { Direct } \\
372\end{array}$ & $\begin{array}{c}0 . \\
\text { Direct } \\
300\end{array}$ & $\begin{array}{c}0 \\
\text { Direct } \\
372\end{array}$ & \begin{tabular}{|c|}
6 \\
Direct \\
300
\end{tabular} & \begin{tabular}{|c}
6 \\
Direct \\
372
\end{tabular} \\
\hline $\begin{array}{l}\text { Energ } \\
y(k)\end{array}$ & 14.5 & 14.8 & 10.4 & 11.6 & 11.4 & 12 & 14.5 & 16.6 & 14.2 & 16.4 & 12.8 & 14.2 \\
\hline $\begin{array}{l}P_{\max } \\
(\mathrm{kN})\end{array}$ & 189 & 204 & 163 & 202 & 160 & 200 & 177 & 203 & 180 & 209 & 160 & 189 \\
\hline CFE & 0.386 & 0.366 & 0.317 & 0.29 & 0.357 & 0.3 & 0.413 & 0.4 & 0.397 & 0.39 & 0.4 & 0.375 \\
\hline $\begin{array}{l}\text { Fus: } \\
(\mathrm{WN})\end{array}$ & 73 & 74.7 & 51.7 & 58.4 & 57.1 & 60.4 & 73.2 & 80.6 & 71.5 & 82.4 & 63.9 & 70.9 \\
\hline
\end{tabular}

Table 6: Summary of crashworthiness parameters for all tube profiles for two different parameters (oblique loading)

\begin{tabular}{|c|c|c|c|c|c|c|c|c|c|c|c|c|}
\hline \multirow[b]{2}{*}{$\begin{array}{l}\text { Indic } \\
\text { ators }\end{array}$} & \multicolumn{2}{|c|}{ Circular } & \multicolumn{2}{|c|}{ Rectangle } & \multicolumn{2}{|c|}{ Square } & \multicolumn{2}{|c|}{ Hexagonal } & \multicolumn{2}{|c|}{ Octagonal } & \multicolumn{2}{|c|}{ Ellipse } \\
\hline & $\begin{array}{c}c \\
\text { Obliq } \\
\text { ue } \\
300\end{array}$ & $\begin{array}{l}\text { C. } \\
\text { Obliq } \\
\text { Ue } \\
372\end{array}$ & $\begin{array}{c}\text { R. } \\
\text { Obliq } \\
\text { ue } \\
300\end{array}$ & $\begin{array}{c}\text { R. } \\
\text { Obliq } \\
\text { Ue } \\
372\end{array}$ & $\begin{array}{c}\text { S. } \\
\text { Obliq } \\
\text { ve } \\
300\end{array}$ & $\begin{array}{c}\text { S. } \\
\text { Obliq } \\
\text { ue } \\
372\end{array}$ & $\begin{array}{c}\mathrm{H} \cdot \\
\text { Obliq } \\
\text { ue } \\
300\end{array}$ & $\begin{array}{c}\mathrm{H} \cdot \\
\text { Obliq } \\
\text { ue } \\
372\end{array}$ & $\begin{array}{c}0 . \\
\text { Obliq } \\
\text { ve } \\
300\end{array}$ & $\begin{array}{c}0 . \\
\text { Obliq } \\
\text { ue } \\
372\end{array}$ & $\begin{array}{c}\text { E. } \\
\text { Obliq } \\
\text { ue } \\
300\end{array}$ & $\begin{array}{c}\text { E. } \\
\text { Obliq } \\
\text { ue } \\
372\end{array}$ \\
\hline $\begin{array}{l}\text { Energ } \\
\mathrm{y}(\mathrm{k})\end{array}$ & 9.2 & 8.6 & 6.7 & 7.3 & 7.3 & 7 & 9.8 & 10 & 9.3 & 10.4 & 8.3 & 10.5 \\
\hline $\begin{array}{l}\text { Pmax } \\
(\mathrm{KN})\end{array}$ & 74.7 & 64.1 & 70.3 & 57.4 & 74.6 & 79.7 & 72.1 & 63.1 & 79.2 & 65 & 64.5 & 72.7 \\
\hline CFE & 0.62 & 0.69 & 0.485 & 0.63 & 0.49 & 0.45 & 0.685 & 0.71 & 0.6 & 0.82 & 0.66 & 0.72 \\
\hline $\begin{array}{l}\text { Faver } \\
\text { age } \\
(\mathrm{KN})\end{array}$ & 46.3 & 44.6 & 34.1 & 36.4 & 36.7 & 35.9 & 49.5 & 44.6 & 48.1 & 53.4 & 42.5 & 52.9 \\
\hline
\end{tabular}

\subsection{Force Displacement Characteristics of different}

\section{geometrical profiles}

Typical force displacement diagrams for each kind of profile tested in this study are presented in Figures $4-9$. Each figure depicts the force response for certain cross sectional geometric profile due to the direct and oblique loading for the two classes of perimeters (300 $\mathrm{mm}$ and $372 \mathrm{~mm}$ respectively). From these figures, it is noticeable that the energy (area under the graph) absorbed by the tubes due to oblique loading is much lower than for direct loading. This is because the oblique loading causes two kinds of mechanical loads onto the tube. These loads are axial compression and bending. That is why the tubes under oblique loading bend while undergoing some form of progressive crushing. Besides this it is evident that the force displacement characteristic for different perimeter within a geometrical profile is rather similar for both axial and oblique 
loading. This is an indication that the perimeter does not play an important role in the folding mechanism (progressive collapse) of the tubes.

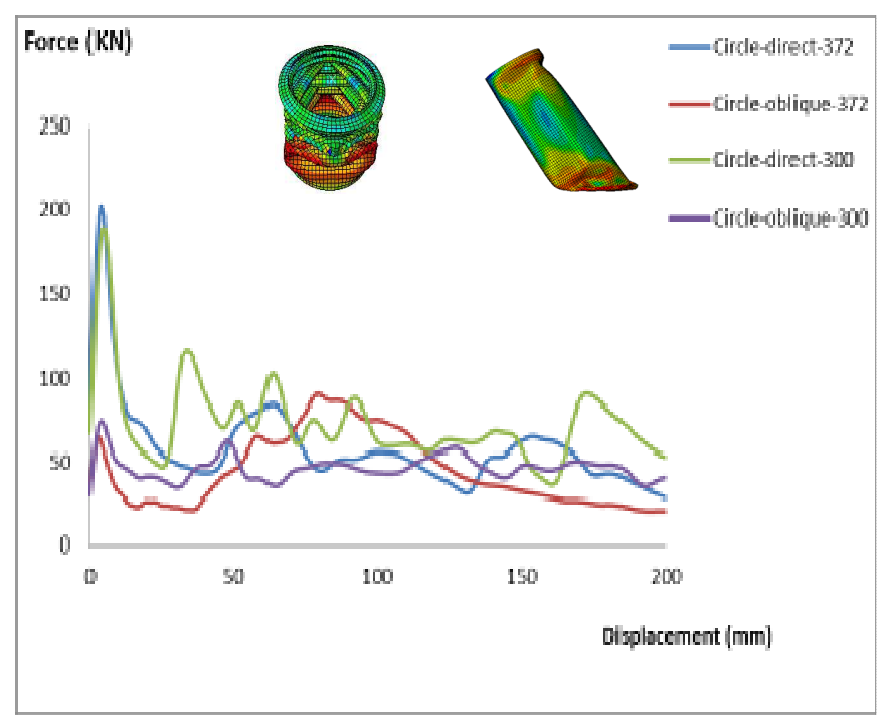

Figure 4: Force vs. displacement for circular tubes (direct and oblique impacts)

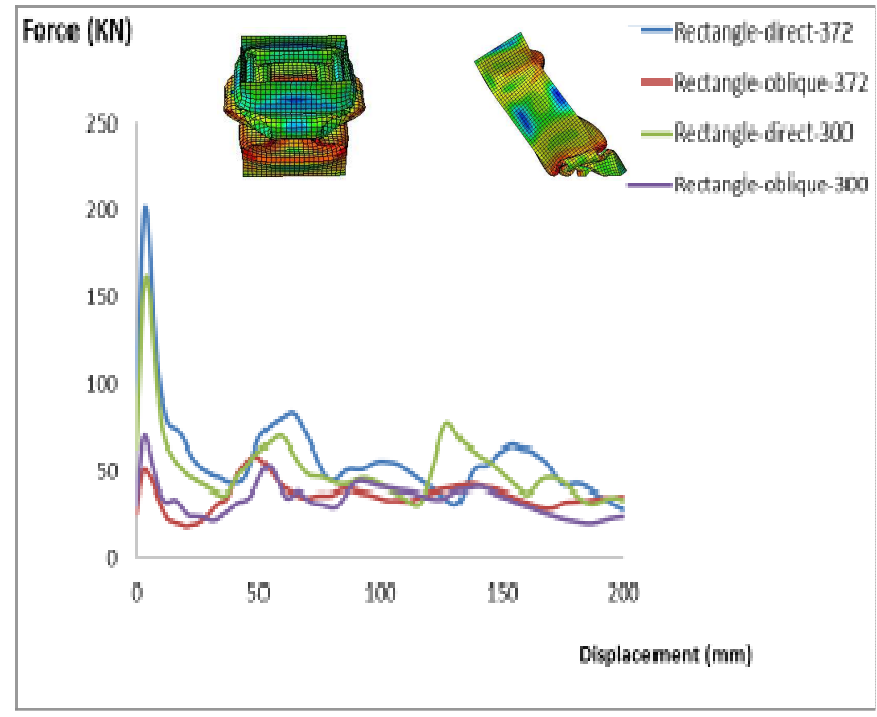

Figure 5: Force vs. displacement for rectangular tubes (direct and oblique impacts)

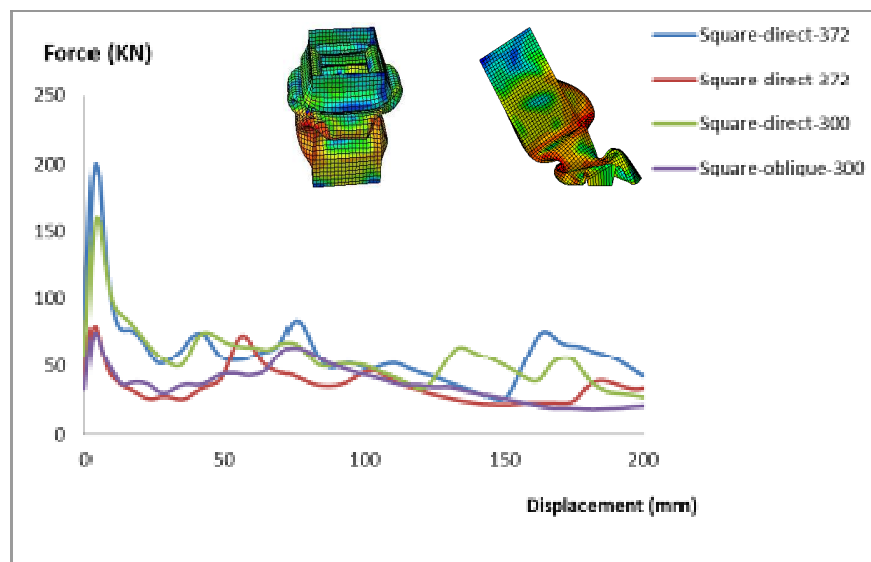

Figure 6: Force vs. displacement for square tubes (direct and oblique impacts)

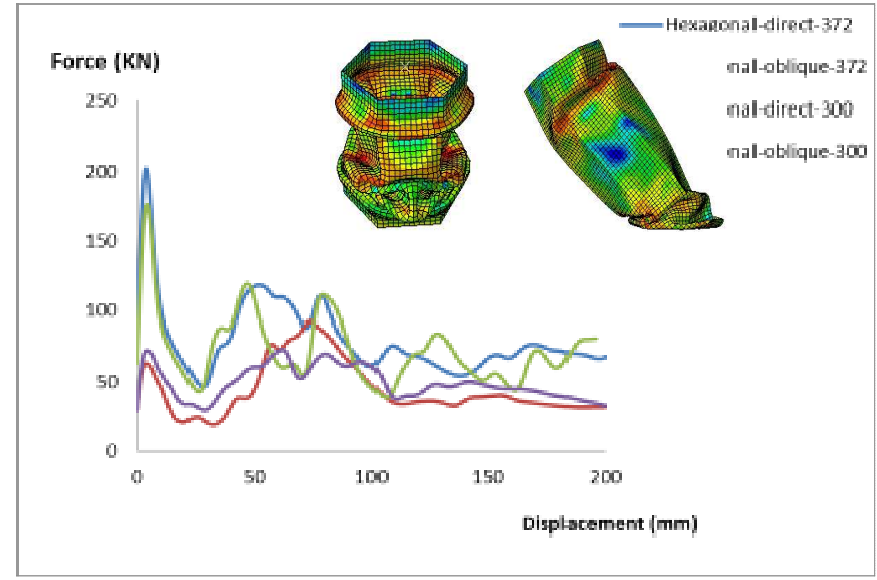

Figure 7: Force vs. displacement for hexagonal tubes (direct and oblique impacts)

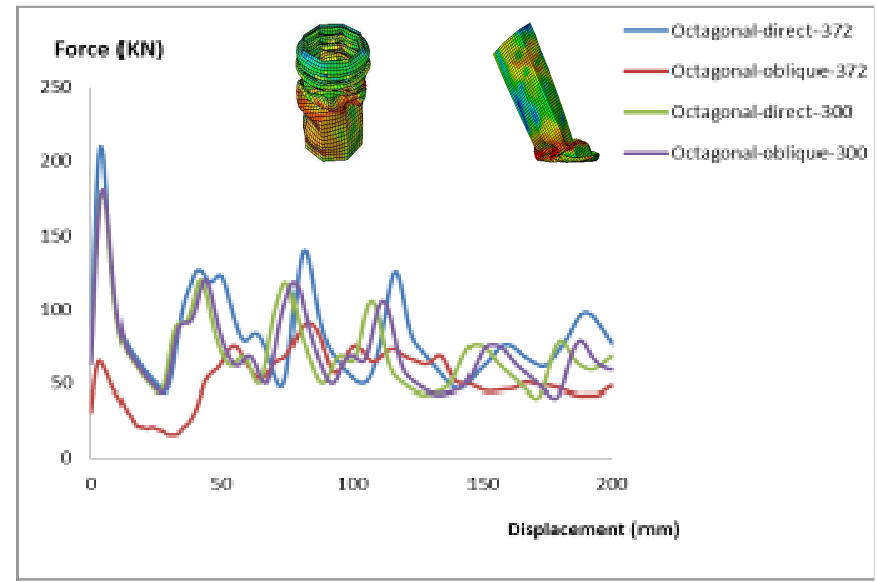

Figure 8: Force vs. displacement for Octagonal tubes (direct and oblique impacts) 


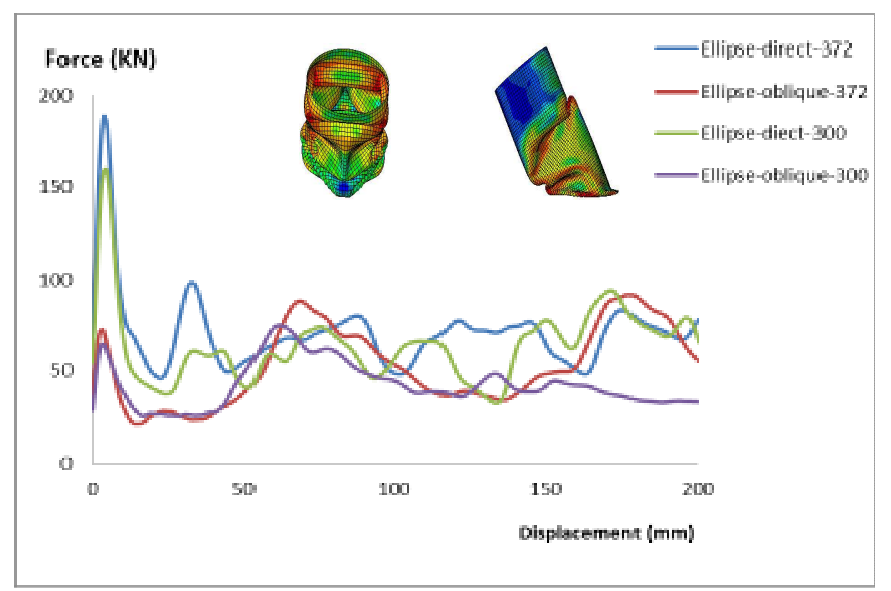

Figure.9: Force vs. displacement for Ellipse tubes (direct and oblique impacts)

\subsection{Energy Absorption}

In Figures 10 and 11, the energy absorption is plotted as function of the deformation length rather than function of time because this facilitates the comparison of different structural design concepts. Based on these figures it can be concluded that rectangle cross sectional geometry has significantly lower energy absorption than the other five profiles for both impact conditions. Also from these figures, the octagonal and hexagonal profiles are better energy absorbers in both loading conditions. A summary of the energy absorption capabilities for all tube profiles are summarized in Figures 12 and 13 for both direct and oblique loading respectively. From here, it can be seen that as the perimeter was increased from $300 \mathrm{~mm}$ to 372 $\mathrm{mm}$, most profiles exhibited a higher energy absorption capability. In terms of specific energy absorption (SEA), the hexagonal tube with a perimeter profile of $300 \mathrm{~mm}$ had the highest SEA compared to the other profiles. This is depicted in Figures 14 and 15 for direct and oblique loading respectively.

Another view of the energy absorption will be investigating the effects of profiles on the energy absorption due to oblique loading. This is depicted in Tables 7 and 8 respectively for both different perimeters under study. In general in can be concluded that profiles studied with oblique loading showed decreasing energy absorption. The percentage of decrease various according to the profile time, but on an overall the difference is between $15-55 \%$ for all profiles. Hexagonal, octagonal and circle are good geometry to be considered since they perform outstanding in terms of energy absorption in both loading and perimeter conditions respectively. The task now is to select the best tube in terms of the geometry profile and also the perimeter. This involves using performance criteria such as energy absorption capabilities; crush force efficiency, cost and manufacturing constraints. This will be discussed next.

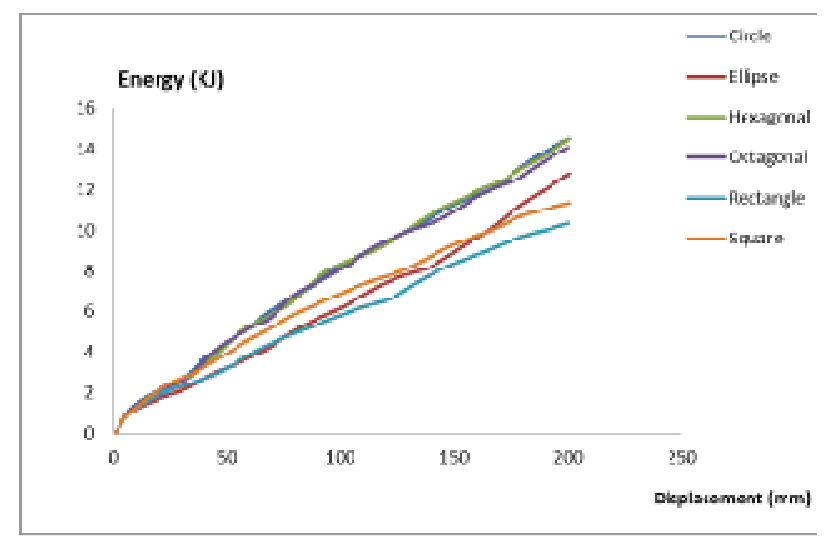

Figure 10: Energy absorption characteristics of six different profiles for direct impact loading with perimeter $372 \mathrm{~mm}$

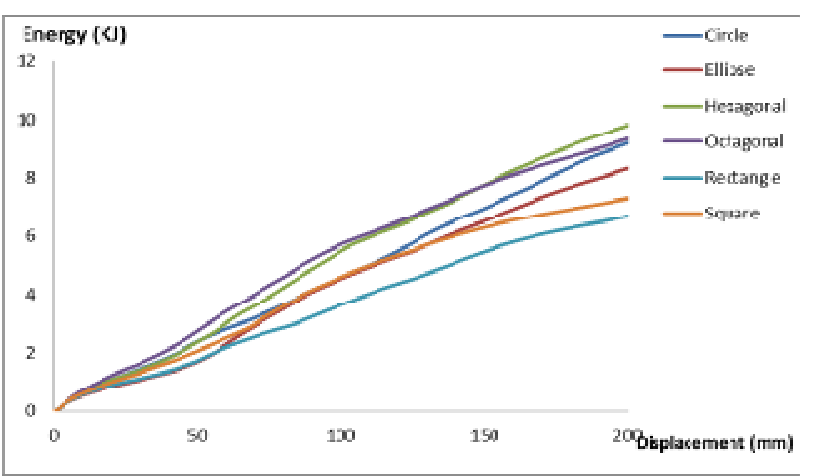

Figure 11: Energy absorption characteristics of six different profiles for oblique impact loading with perimeter $300 \mathrm{~mm}$

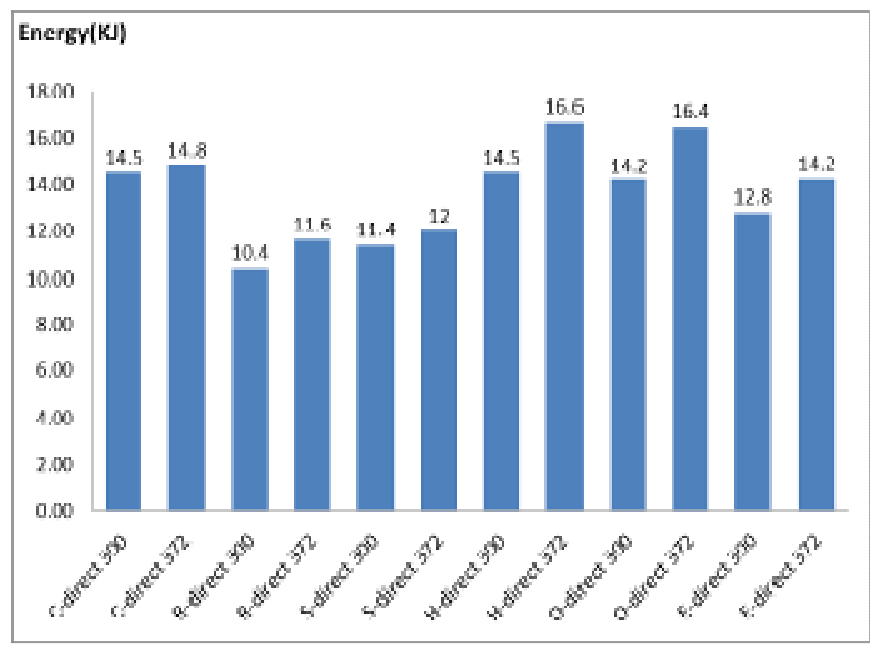

Figure 12: Energy absorption capability for various profiles due to direct loading condition. 


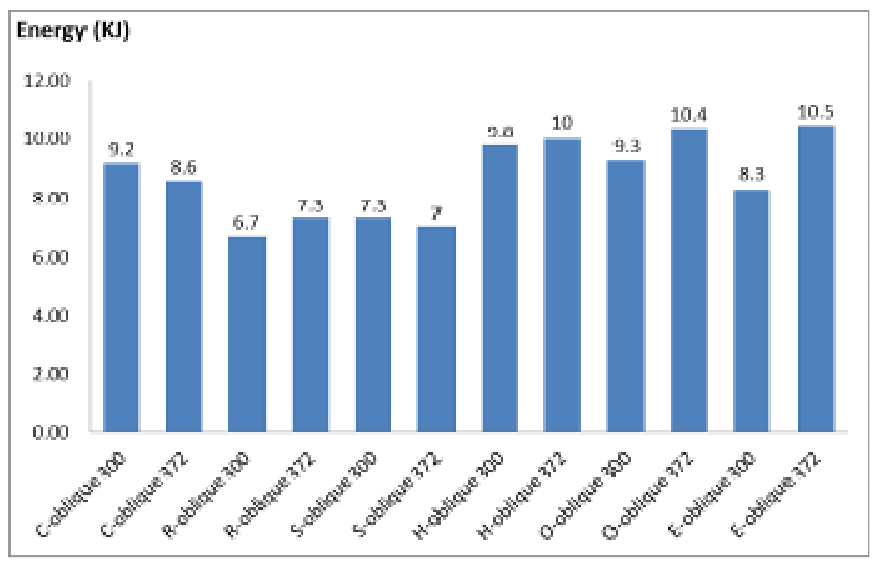

Figure 13: Energy absorption capability for various profiles due to oblique loading condition.

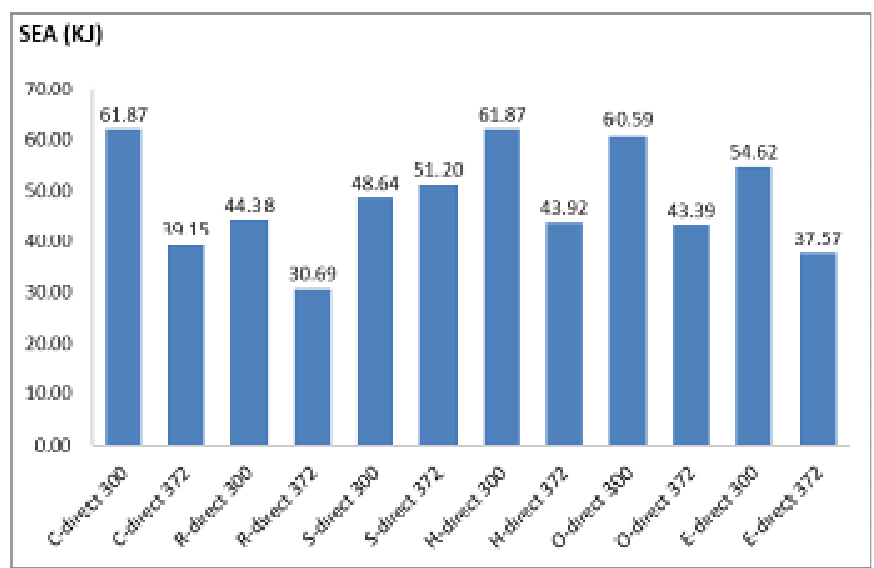

Figure 14: Specific energy absorption capability for various profiles due to direct loading condition.

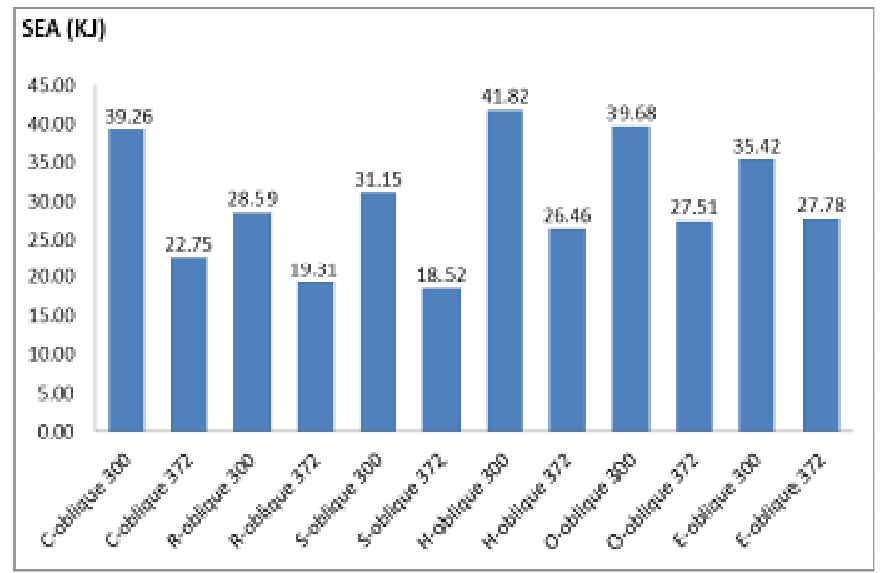

Figure 15: Specific energy absorption capability for various profiles due to oblique loading condition.
Table 7: Energy absorption of six profiles with three two different load conditions

\begin{tabular}{|c|c|c|}
\hline \multirow[b]{2}{*}{ Shope } & \multicolumn{2}{|c|}{ Perimeter $372 \mathrm{~mm}$} \\
\hline & $\begin{array}{l}\text { Energy obsorpbon (kJ) } \\
\text { Direct impact } \\
200 \text { min deformation }\end{array}$ & $\begin{array}{l}\text { Energy absorptoon ( } \mathrm{kJ} \text { ) } \\
\text { Oblique impact } \\
200 \mathrm{~min} \text { deformation }\end{array}$ \\
\hline Circle & 14.8 & $\begin{array}{c}8.6 \\
41.9 \% \\
\end{array}$ \\
\hline nectangle & 11.6 & $\begin{array}{l}7.3 \\
-37 \%\end{array}$ \\
\hline Square & 12 & $\begin{array}{c}7 \\
-41.7 \%\end{array}$ \\
\hline Hexseonal & 16.6 & $\begin{array}{c}10 \\
-39.7 \%\end{array}$ \\
\hline Octagonal & 16.4 & $\begin{array}{r}10.4 \\
-36.65 \%\end{array}$ \\
\hline Ellipse & 14.2 & $\begin{array}{l}10.5 \\
-26 \%\end{array}$ \\
\hline
\end{tabular}

Table 8: Energy absorption of six profiles with three two different load conditions

\begin{tabular}{|c|c|c|}
\hline \multirow[b]{2}{*}{ Shape } & \multicolumn{2}{|c|}{ Perimeter $300 \mathrm{~mm}$} \\
\hline & $\begin{array}{l}\text { Energy absorption (kJ) } \\
\text { Direct Impact } \\
200 \mathrm{~mm} \text { deformation }\end{array}$ & $\begin{array}{c}\text { Energy absorption ( } \mathrm{kJ} \text { ) } \\
\text { Oblique Impact } \\
200 \mathrm{~mm} \text { deformation }\end{array}$ \\
\hline Circle & 14.5 & $\begin{array}{c}9.2 \\
-36.5 \%\end{array}$ \\
\hline Fectangle & 10.4 & $\begin{array}{c}6.7 \\
-35.5 \%\end{array}$ \\
\hline Square & 11.4 & $\begin{array}{c}7.3 \\
-36 \% \\
\end{array}$ \\
\hline Hexagonal & 14.5 & $\begin{array}{c}9.8 \\
-32.4 \%\end{array}$ \\
\hline Octagonal & 14.2 & $\begin{array}{c}9.3 \\
-34.5 \%\end{array}$ \\
\hline Ellipse & 12.8 & $\begin{array}{c}8.3 \\
-35.1 \%\end{array}$ \\
\hline
\end{tabular}

\subsection{Selection of Best Profile}

For the multi criteria decision making (MCDM) process, the complex proportional assessment method (COPRAS) was chosen. This method was chosen for its simplicity in usage. The method assumes direct and proportional dependences of the significance and utility degree of the available alternatives under the presence of mutually conflicting criteria. It takes into account the performance of the alternatives with respect to different criteria and the corresponding criteria weights. This method selects the best decision considering both the ideal and the ideal-worst solutions. The details of this method have been presented in the previous section. The first step is to determine the associated weightage for each performance criteria. This is depicted in Table 9. Once the weightages have been assigned to the respective indicators, the decision matrix, as shown in Table 10 is normalized using Eq. (7) and the corresponding weighted normalized decision matrix is developed, as given in Table 11. 
The purpose of normalization is to obtain dimensionless values of different performance indicators so that all these criteria can be compared. This is followed by the computing the sums of the weighted normalized values for both the beneficial attributes and non-beneficial attributes as given in Table 12. In this case the only non-beneficial attribute is the ratio indicator where a lower value is preferred. Then, applying Eq. (14) the relative significance or priority value (Qi) for each tube concept is determined, as shown in Table 13. Table 13 also exhibits the value of quantitative utility (Ui) for each tube concept on the basis of which the complete ranking of the tube concept is obtained. The candidate tube for designing an efficient energy absorber is hexagonal with a perimeter of $300 \mathrm{~mm}$, followed by hexagonal with a perimeter of $372 \mathrm{~mm}$. The worst concept is the square profile. Hence, it is the hexagonal tube with a perimeter of $300 \mathrm{~mm}$ that was chosen for the next phase of study which is to investigate the effects of thickness and foam filling in the enhancement of energy absorption.

Table 9: Weightage setting for each performance indicator

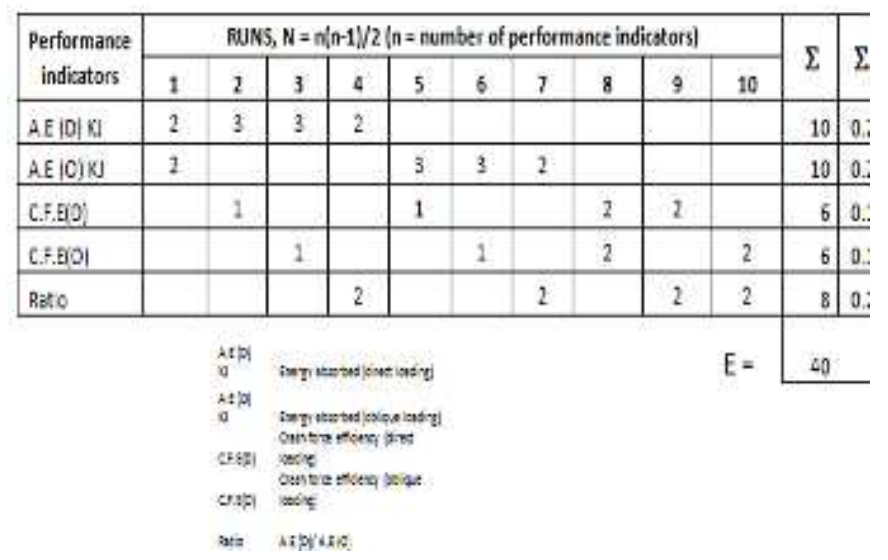

Table 10: Data of performance indicators in a decision matrix

\begin{tabular}{|c|c|c|c|c|c|}
\hline \multirow{4}{*}{ Specimens } & \multicolumn{5}{|c|}{ Woightages } \\
\hline & 0.25 & 0.25 & 0.15 & 0.15 & 0.2 \\
\hline & \multicolumn{5}{|c|}{ Performance indicators } \\
\hline & S.E.A (D) & S.L.A (O) & CFLL(D) & CFL(O) & Ratio \\
\hline C. 300 & 6187 & 39.26 & 38.6 & 62 & 157 \\
\hline c_- 372 & 39.15 & 22.75 & 36.6 & 69.5 & 1.72 \\
\hline $\mathrm{R} 300$ & 4438 & 2859 & 31.7 & 485 & 155 \\
\hline$R-372$ & 30.69 & 19.31 & 29 & 63 & 159 \\
\hline S_ 300 & 18.64 & 91.15 & 35.7 & 49 & 1.56 \\
\hline $5 \_372$ & 51.2 & 18.52 & 30 & 45 & 1.71 \\
\hline$H_{2} 300$ & 61.87 & 41.82 & 41.3 & 68.5 & 1.48 \\
\hline $\mathrm{H} 372$ & 4392 & 26.46 & 40 & 71 & 1.66 \\
\hline 0.300 & 6059 & 3968 & 39.7 & 60 & 152 \\
\hline $0 \_372$ & 43.39 & 2751 & 39 & B2 & 1.57 \\
\hline E-300 & 54.62 & 35.42 & 40 & 66 & 154 \\
\hline E. 372 & 37.57 & 27.78 & 37.5 & 73 & 1.35 \\
\hline
\end{tabular}

Table 11: Weighted normalized decision matrix

\begin{tabular}{|c|c|c|c|c|c|}
\hline \multirow{4}{*}{ Specimens } & \multicolumn{5}{|c|}{ Welghtnges } \\
\hline & 0.25 & 0.25 & 0.15 & 0.15 & 0.2 \\
\hline & \multicolumn{5}{|c|}{ Performance indicators } \\
\hline & A.E (D) & $A, E(0)$ & CFE(O) & CFE(O) & Ratio \\
\hline C_300 & 0.0267 & 0.027 & 0.013 & 0.0122 & 0.0166 \\
\hline C. 372 & 0.0169 & 0.015 & 0.0125 & 0.0137 & 0,0182 \\
\hline R_jo0 & 0.0191 & 0.019 & 0.0108 & 0.0096 & 0.0164 \\
\hline R. 372 & 0.0132 & 0.013 & 0.0099 & 0.0124 & 0.0168 \\
\hline S_s00 & 0.021 & 0.021 & 0.012 & 0.0097 & 0.0165 \\
\hline 5. 372 & 0.022 & 0.0129 & 0010 & 0.0089 & 0.0181 \\
\hline$H_{-} 300$ & 0.026 & 0.0291 & 0,014 & 0.0135 & 0.0157 \\
\hline $\mathrm{H} \_372$ & 0.019 & 0.0184 & 0.013 & 0.0140 & 0.0176 \\
\hline $0 \_300$ & 0.026 & 0.027 & 0.0135 & 0.0118 & 0.0161 \\
\hline 0.372 & 0.018 & 0019 & 0.0133 & 00162 & 00166 \\
\hline E. 900 & 0.023 & 0.024 & 0.0136 & 0.0130 & 0.0163 \\
\hline$=372$ & 0.016 & 0.0193 & 0.0128 & 0.0144 & 0.0143 \\
\hline
\end{tabular}

Table 12: Sums of the weighted normalized values

\begin{tabular}{|c|c|c|}
\hline Specimens & $\begin{array}{c}\text { Beneficial } \\
\text { Si+ }\end{array}$ & $\begin{array}{c}\text { Non- } \\
\text { Beneficial } \\
\text { Si- }\end{array}$ \\
\hline C_300 & 0.079 & 0.018 \\
\hline C_372 & 0.059 & 0.015 \\
\hline R_300 & 0.059 & 0.014 \\
\hline R_372 & 0.049 & 0.016 \\
\hline S_300 & 0.064 & 0.021 \\
\hline S_372 & 0.054 & 0.022 \\
\hline H_300 & 0.083 & 0.016 \\
\hline H_372 & 0.065 & 0.019 \\
\hline O_300 & 0.079 & 0.019 \\
\hline O_372 & 0.067 & 0.016 \\
\hline E_300 & 0.075 & 0.012 \\
\hline E_372 & 0.063 & 0.013 \\
\hline$\sum$ & 0.8000 & 0.2000 \\
\hline
\end{tabular}


Table 13: Qi and Ui values

\begin{tabular}{|c|c|c|c|}
\hline Specimens & Q & U & Rank \\
\hline CIR_300 & 0.094 & 94.1 & 3 \\
\hline CIR_372 & 0.077 & 76.7 & 10 \\
\hline Rec_300 & 0.079 & 78.5 & 8 \\
\hline Rec_372 & 0.066 & 65.7 & 12 \\
\hline Sq_300 & 0.0776 & 77.1 & 9 \\
\hline Sq_372 & 0.066 & 66.1 & 11 \\
\hline Hex_300 & 0.1 & 100 & 1 \\
\hline Hex_372 & 0.079 & 79 & 7 \\
\hline Oct_300 & 0.093 & 93 & 4 \\
\hline Oct_372 & 0.084 & 84 & 5 \\
\hline ELL_300 & 0.098 & 97 & 2 \\
\hline ELL_372 & 0.084 & 83.3 & 6 \\
\hline
\end{tabular}

\subsection{Effect on Foam On Energy Absorption}

In this phase of study, the selected tube from phase 1, namely the hexagonal tube with a perimeter of $300 \mathrm{~mm}$ was further investigated in terms of tube wall thickness and foam filling. The wall thickness selected were $1 \mathrm{~mm}, 2 \mathrm{~mm}$ and $3 \mathrm{~mm}$ respectively. Table 14 shows that the using of foam enhances both energy absorption and CFE, increases energy from $14.5 \mathrm{KJ}$ to $60.2 \mathrm{KJ}$ for the same deformation length.

Table 14: Effect of using foam and trigger on the magnesium tube subjected to axial loading

\begin{tabular}{|l|l|l|l|}
\hline profile & hexagonal & With foam & With trigger \\
\hline $\begin{array}{l}\text { Energy } \\
\text { absorption }\end{array}$ & $14.5 \mathrm{KJ}$ & $60.2 \mathrm{KJ}$ & $13.85 \mathrm{KJ}$ \\
\hline CFE & $41 \%$ & $52 \%$ & $44.7 \%$ \\
\hline
\end{tabular}

\subsection{Effect on Trigger Mechanism}

Circular, square and elliptical were used in this study. Circular trigger shown the best values. It was shown that the distribution of holes in non-neighbors side is the best choice. These six holes distributed on three sides as two holes in each side. Three reduction percentage also used $5,10,15 \%$ the $10 \%$ reduction shows the best selection. Different trigger position used, 10, 20, $30,40,50,60$ and $70 \mathrm{~mm}$ of the edge used, the $50 \mathrm{~mm}$ of trigger location reveals the best selection.as shown in table 14 the trigger increase the CFE by $9 \%$. Using trigger decreases the peak load by $12.5 \%$ which decreases the force transmitted to the passengers.

\section{CONCLUSIONS}

A numerical investigation of both the axial and oblique crush response of thin walled has been done. Ductile metallic Magnesium alloy (AZ31) of various cross sectional profiles was performed. The investigation was broken up into three phases: (1) the investigation of individual cross sectional profile and the selection of the best profile, (2) the investigation of tube foam filling on the crush response on the chosen profile and finally (3) the effect of trigger mechanism onto the selected profile design. All simulations were dynamic with an impact speed of $15 \mathrm{~m} / \mathrm{s}$ and impact mass of $275 \mathrm{~kg}$. Oblique loading was simulated at a 30deg angle to the tube's axial direction. It was found that the hexagonal profile was a better concept for energy absorption application taking into accounts the crash performance indicators as well as the cost and manufacturing feasibility. The $2 \mathrm{~mm}$ thickness hexagonal tube had energy absorption of $14.5 \mathrm{~kJ}$ and a CFE of 0.41 for direct loading and $9.8 \mathrm{~kJ}$ and CFE of 0.68 for oblique loading respectively. When foam filling was added, the crash performance indicators improved. For direct and oblique loading, the $2 \mathrm{~mm}$ thickness hexagonal tube had energy absorption of $60.2 \mathrm{~kJ}$ and a CFE of 0.52 for direct and $29.5 \mathrm{KJ}$ and 0.86 for oblique loading. This is a mark improvement for the oblique impact crush performance. Finally, the trigger mechanism in form of a hole induced in the tube, helped to lower the peak force and improve the crash force efficiency from 0.41 to 0.447 and reduces the peak force from $177 \mathrm{KN}$ to $155 \mathrm{KN}$ in direct loading. This is partly due to the more effective progressive crushing that was introduced by the trigger mechanism. In conclusion, it can be said that the hexagonal tube of wall thickness $2 \mathrm{~mm}$ and with aluminum foam filling and a trigger mechanism has shown to be a good potential energy absorber candidate for crashworthiness application in helping mitigating serious injuries to the occupant of the vehicle.

\section{REFERENCES}

[1] G D Jacobs and Amy Aeron-Thomas. A review of global road accident fatalities.

[2] Ramakrishna S, Hamada H, Energy absorption characteristics of crashworthy structural composite materials. Key Engineering Materials; 1998: 141-143: 585-620.

[3] A.G. Olabi, Edmund Morris, M.S.J. Hashmi. Metallic tube type energy absorbers: A synopsis. Thin Walled Structures 45 (2007) 707 - 726.

[4] Gregory Nagel. 2005. Impact and Energy Absorption of Straight and Tapered Rectangular Tubes. PhD Study. Queensland University of Technology, Australia.

[5] Borvik, T., Hopperstad, O.S. Reyes, A., Langseth, M., Solomos, G and Dyngeland, T. Empty and foam filled circular aluminium tubes subjected to axial and oblique quasi static loading. International Journal of Crashworthiness. 8 (2003): 481 - 494 
[6] Reyes, A., Langseth, M. and Hopperstad, O.S. Crashworthiness of aluminium subjected to oblique loading: experiments and numerical analyses. International Journal of Mechanical Sciences. 44 (2002): $1965-1984$

[7] Reyes, A., Langseth, M. and Hopperstad, O.S. Aluminium foam filled extrusions subjected to oblique loading: experiments and numerical analyses. International Journal of Solids and Structures. 44 (2002): $1645-1675$

[8] Reyes, A., Langseth, M. and Hopperstad, O.S. Square aluminium tubes subjected to oblique loading. International Journal Of Impact Engineering. 28(10)(2003): 1077 - 1106

[9] Reid, S.R. and Reddy, T.Y. Static and dynamic crushing of tapered sheet metal tubes of rectangular cross section. International Journal of Mechanical Sciences. 28 (1986): $623-637$

[10] Yong-Bum Cho, Chul-Ho Bae, Myung-Won Suh, HyoChol Sin. A vehicle front frame crash design optimization using hole-type and dent-type crush initiator. Thin Walled Structures 44 (2006): 415 - 428.

[11] Reddy, T.Y., Wall, R.J. Axial compression of foam filled thin walled circular tubes. International Journal of Impact Engineering. 7(2)(1988): $151-166$

[12] Sherwood, J.A. and Frost, C.C. Constitutive Modeling and Simulation of Energy Absorbing Polyurethane foam under Impact loading. Polymer Engineering and Science. 32(16) (1992): 1138 - 1146.

[13] Seitzberger, M., Rammerstorfer, F.G., Gradinger, R., Degischer, H.P., Blaimachein, M., Walch, C. Experimental studies on the quasi static axial crushing of steel columns filled with aluminium foam. International Journal of Solids and Structures. 37(30)(2000): 4125 4147

[14] Toksoy, A.K., Guden, M. The strengthening effect of polystyrene foam filling in aluminium thin walled cylindrical tubes. 43 (2)(2005): 333- 350

[15] F. Tarlochan, S. Ramesh, S. Harpreet. Advanced composite sandwich structure design for energy absorption applications: Blast protection and crashworthiness. Composites Part B: Engineering. 43(5)(2012): $2198-2208$

[16] F. Tarlochan, S. Ramesh. Composite sandwich structure with nested inserts for energy absorption application. Composite Structures. 94 (3) (2012): 904 - 916.

[17] F. Tarlochan, A.M.S Hamouda, B.B. Sahari, E. Mahdi. Composite sandwich structures for crashworthiness applications. Proceedings of the Institution of Mechanical Engineers, Part L: Journal Of Material: Design and Application 221 (2) (2007): 121 - 130.

[18] L. Lanzi, L.M.L. Castelletti, M. Anghileri. Multi objective optimization of composite absorber shape under crashworthiness requirements. Composite Structures. 65 (2004): 433 - 441
[19] O. Fyllingen, O.S. Hopperstad, A.G. Hanssen, M. Langseth. Modelling of tubes subjected to axial crushing. ThinWall Structures. 48 (2010): $134-142$.

[20] L. Lanzi, L.M.L. Castelletti, M. Anghileri. Multi objective optimization of composite absorber shape under crashworthiness requirements. Composite Structures. 65 (2004): 433 - 441

[21] S. Chung Kim Yuen, G.N. Nurick and R.A. Starke, 2008, The energy absorption characteristics of double-cell tubular profiles, Latin American Journal of Solids and Structures 5 (2008)289-317.

[22] Qingwu Cheng, William Altenhof and Li Lib, 2006, Experimental investigations on the crush behaviour of AA6061-T6 aluminum square tubes with different types of through-hole discontinuities, Thin-Walled Structures 44 (2006) 441-454.

[23] C. Graczykowski, G. Mikułowski \& J. Holnicki-Szulc, Adaptive impact absorption - a benchmark and an example Absorber, Institute of Fundamental Technological Research Polish Academy of Sciences (IPPT PAN), Warsaw, Poland.

[24] Anne-Marie Harte, Norman A. Fleck and Michael F. Ashby, 2000, Energy absorption of foam-filled circular tubes with braided composite walls, Eur. J. Mech. A/Solids 19 (2000) 31-50.

[25] A.G. Olabi, E. Morris, M.S.J. Hashmi, M.D. Gilchrist. Optimised design of nested circular tube energy absorbers under lateral impact loading. International Journal of Mechanical Sciences. 50 (2008): $104-116$

[26] Z. Ahmad, D.P. Thambiratnam. Dynamic computer simulation and energy absorption of foam-filled conical tubes under axial impact loading. Computers and Structures 87 (2009): 186-197.

[27] Avinash P. Deshpande, 2005, Finite Element Study of Energy Absorption in Corrugated Beams, Wichita State University, 2005.

[28] Nirut Onsalung, Chawalit Thinvongpituk and Kulachate Painthong, 2010. The Influence of Foam Density on Specific Energy Absorption of Rectangular Steel Tubes, Energy Research Journal 1 (2): 135-140, 2010, ISSN 1949-0151.

[29] Yanshan Lou, Chunghee Park, Hoon Huh, 2008, Parameter study on the quasi-statically axial crush of frusta with small semiapical angles using finite element method, KSAE 2008 Annual Conference.

[30] Prasenjit Chatterjee, Vijay Manikrao Athawale, Shankar Chakraborty, 2011. Materials selection using complex proportional assessment and evaluation of mixed data methods. Materials and Design. 32: 851-860

[31] B. Dehghan-Manshadi, H. Mahmudi, A. Abedian, R. Mahmudi, 2007. A novel method for materials selection in mechanical design: Combination of non-linear normalization and a modified digital logic method. Materials and Design. 28: 8-15. 
[32] G.M. Nagel, D.P. Thambiratnam, 2005, Computer simulation and energy absorption of tapered thin-walled rectangular tubes, Thin-Walled Structures 43 (2005) 1225-1242.

[33] W.J. Witteman 1999. Improved Vehicle Crashworthiness Design by Control of the Energy Absorption for Different Collisions Situation. PhD Study. Eindhoven University of Technology, Netherlands.

\section{BIOGRAPHIES}

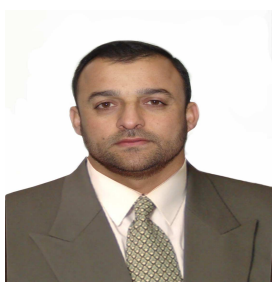

Samer F. was born in Iraq He obtained his Bachelors in Mechanical Engineering and Masters in Engineering from IRAQ. $\mathrm{He}$ is currently pursuing his $\mathrm{PhD}$ at UNITEN in the field of applied mechanics.

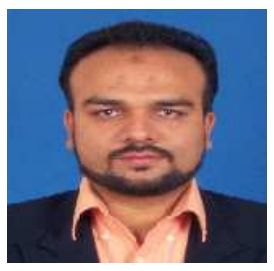

F. Tarlochan was born in Malaysia. $\mathrm{He}$ obtained his Bachelors in Mechanical Engineering and Masters in Biomedical Engineering from Purdue University, USA. His $\mathrm{PhD}$ was from Universiti Putra Malaysia. He is currently an Associate Professor at UNITEN and heads the Center for Innovation and Design. Email: faristarlochan@gmail.com 